\section{Financial Crisis in Portugal: Effects in the Health Care Sector}

International Journal of Health

Services

0 (0) $1-23$

(C) The Author(s) 2019

Article reuse guidelines: sagepub.com/journals-permissions DOI: $10.1|77 / 002073| 4 \mid 8822227$

journals.sagepub.com/home/joh

@SAGE

\author{
Alexandre Morais Nunes',2, \\ Diogo Cunha Ferreira ${ }^{2}$ (D) and \\ Adalberto Campos Fernandes ${ }^{3}$
}

\begin{abstract}
Portugal has faced an economic and financial crisis that began circa FY2009 and whose effects are still ongoing. In FY20II, the Portuguese state and the European triumvirate - composed of the European Commission, the International Monetary Fund, and the European Central Bank - signed the Memoranda of Understanding. This troika agreement aimed to improve the operational efficiency of public services. This crisis had a considerable impact on the Portuguese citizens' life and productivity, as well as on the public health care system. Cuts over public expenditures have been made to reduce the risk of noncompliance with budgetary targets, despite their potential impact on quality and access to health care services. We analyzed the main policies and measures undertaken by the Portuguese Ministry of Health with respect to the bailout program associated with the troika agreement. Then, we focused on the budgetary cuts-related risks over the social performance of the care system. Evidence suggests that structural reforms in the health care sector in the troika period had positive effects in terms of drugs administration and consumption, on the one hand, and secondary care expenditures reduction, on the other hand. Nonetheless, we observed some divestitures on infrastructures and the worsening of access to health care services.
\end{abstract}

'CAPP, Instituto Superior de Ciências Sociais e Políticas, Universidade de Lisboa, Lisbon, Portugal

${ }^{2}$ CERis, Instituto Superior Técnico, Universidade de Lisboa, Lisbon, Portugal

${ }^{3}$ Escola Nacional de Saúde Pública, Universidade Nova de Lisboa, Lisbon, Portugal

Corresponding Author:

Diogo Cunha Ferreira, CESUR, CERis, Instituto Superior Técnico, Universidade de Lisboa, Av. Rovisco Pais I, 1049-00I Lisbon, Portugal.

Email: diogo.cunha.ferreira@tecnico.ulisboa.pt 


\section{Keywords}

Portuguese financial crisis, National Health Service, health care, efficiency, access

\section{Key Messages}

- The effects of the financial crisis in the Portuguese public health care sector were evaluated.

- This study analyzed the main responses given by the Portuguese health care system to the bailout program, focusing on budgetary cuts-related risks over the social performance of the care system.

- Evidence suggests that structural reforms in the health care sector in that period had positive effects in terms of both medicines administration and consumption and secondary care expenditures reduction.

- Nonetheless, divestitures on equipment and infrastructures, as well as the decreasing of access to health care, were also observed.

\section{Introduction}

The Portuguese National Health Service (NHS) delivers universal, equitable, general, and tendentiously free health care services to all citizens. ${ }^{1}$ Planning, organizing, and regulating the health care sector is carried out centrally by the Ministry of Health and, at the regional level, by 5 regional health administrations (RHA; in Portuguese: Administrações Regionais de Saúde, ARS): North, Center, Lisbon and Tagus Valley, Alentejo, and Algarve. ${ }^{2}$ Each RHA has an administrative council, which manages the delivered health care services, ensures the coordination between the public and the private sectors as well as the timely provision of health care to the patients, supervises and controls secondary care providers (hospitals), and, finally, administers and participates in the annual financing process carried out for each primary health care center. ${ }^{2}$

Besides the NHS, the Portuguese health sector is composed of private voluntary insurance (PVI) and a set of health care subsystems: special public and private insurance schemes associated with some professions $(20 \%-25 \%),{ }^{3,4}$ In Portugal, health care providers can be either public (primary health care centers and hospitals) or private. ${ }^{5}$ Public hospitals and primary health care centers are under the supervision and jurisdiction of the Ministry of Health. Private health care providers are mainly clinics and hospitals. These private providers are associated with the delivery of clinical material and pharmaceutical products, with complementary diagnostic and therapeutic services, and with the provision of specialty medical appointments.

The financing of the health care system in Portugal is mainly public, and funds are collected via taxation, ${ }^{4}$ as usual in Beveridge-like systems. 
As mentioned in the Physicians for a National Health Program (http://www. pnhp.org/single_payer_resources/health_care_systems_four_basic_models.php), "in this system [Beveridge], health care is provided and financed by the government through tax payments [ . . . ]. Many, but not all, hospitals and clinics are owned by the government; some doctors are government employees, but there are also private doctors who collect their fees from the government." The Portuguese NHS follows the Britain's one, as both are Beveridge systems. Nevertheless, a significant share of total financing is private and includes co-payments, subsystems, and PVIs that are voluntary, competitive, and excludable services. Whereas subsystems cover nearly a quarter of all Portuguese citizens (in FY2016), that share reduces to $20 \%$ in the case of PVIs. ${ }^{4}$ In FY2016, about $61 \%$ of health care services were financed through public sources, and $29 \%$ resulted from co-payments (or moderating fees). ${ }^{7}$ In the same year, health care expenses represented about $9 \%$ of the Portuguese gross domestic product (GDP). ${ }^{6,7}$

The financial crisis began in FY2009, according to the technical definition of recessions ( 2 quarters of negative growth). ${ }^{46}$ This crisis had a meaningful impact in the Portuguese economy, because of the global recession of worldwide economies. Between FY2010 and FY2011, the Portuguese GDP decreased nearly $4.4 \%$, which compares with the average GDP evolution of EU28: $-2.9 \%$ in the same period. ${ }^{6}$ In FY2011, the Portuguese state and the European triumvirate - composed of the European Commission, the International Monetary Fund, and the European Central Bank - signed the Memoranda of Understanding. These memoranda consisted of 3 main documents: the Memorandum of Economic and Financial Policies, the Technical Memorandum of Understanding, and the Memorandum of Understanding on Specific Economic Policy Conditionality (hereinafter, MoU). These 3 documents are commonly known as the "troika agreement."

After intervention (by December FY2015), the Portuguese GDP rose almost $3 \%$, which was above the EU28 average: $0.7 \%{ }^{6}$ Although the Portuguese public budget deficit (difference between expenditures and revenues) had evolved from $-€ 14,278$ million to $-€ 5,606$ million, this one remained excessively large and led to a substantial increase of the public debt. This debt was fixed into $129 \%$ of GDP in the after-crisis period. ${ }^{8}$

Austerity-based policies included in the troika agreement ${ }^{9}$ also introduced a set of measures to reduce costs and waste in the health system, to improve its efficiency, to increase the regulation of the pharmaceutical market, and to enhance the hospitals' management, by reducing contracted budgets with these entities. ${ }^{5,10}$ Hence, between FY2011 and FY2015, the average household disposable income has decreased, whereas the NHS co-payments have increased. ${ }^{11}$ Henceforward, the access to the NHS and to the appropriate health care services was theoretically worsened within the troika period. 
This study analyzes some of the most important macroeconomic indicators, the existing evidence in official published reports, and the main health policies implemented in the period of troika agreement (FY2011-FY2015). We intend to provide a deep thought about both past and ongoing health policies to recover the Portuguese NHS and to improve the access of citizens to the appropriate and timely health care services. Additionally, we conduct an econometric analysis to investigate the evolution of hospitals' performance between FY2013 and FY2016 and to complement the theoretical analysis. Such an econometric exercise is based on robust nonparametric benchmarking methods linked to an augmented Hicks-Moorsteen Index, which was recently proved to be a true total factor productivity index. It can decompose the performance evolution of hospitals on their efficiency growth, their productivity change (technological evolution), and their approach to or departure from the optimal scale.

The remainder of this study is structured as follows. Section "Health Care Expenditures and Financing Public Providers in Portugal" describes the evolution of expenditures with health care and the financing of public providers in Portugal. Section "Health Policies and the Memoranda of Understanding" describes the main health policies undertaken in the troika agreement period. Section "The Application of Austerity Measures and Their Effects in the Health Sector" identifies the main outcomes resulting from the austerity measures. Section "An Econometric Analysis" details and applies some econometric techniques to study the Portuguese public hospitals' performance evolution between FY2013 and FY2016. Section "Current Policies to Retrieve the National Health Service" describes some health policies introduced by the current government to overcome some of the identified outcomes resulting from the austerity period. Section "Conclusions" concludes this document.

\section{Health Care Expenditures and Financing Public Providers in Portugal}

The public health care system is a Beveridge system like the one existing in Britain and Spain. The Ministry of Health receives a share of the general state budget resulting from taxation of citizens and companies. That budget share is then distributed to all public institutions belonging to the NHS, according to their past expenditures and production (volume of delivered services). ${ }^{12}$ Such a process requires a contracting mechanism between each public entity and its corresponding RHA. ${ }^{13}$ For instance, the hospitals' contracted budget requires the prospecting of the diagnostic-related groups-based activity, as well as a set of service-specific prices. These prices are defined by clustering hospitals according to a set of size- and complexity-related variables, finding the most efficient hospitals within each cluster, and assessing their associated unitary costs. 
The evolution of expenses with health care in the past few years has been associated with an attempt to control the public share of those expenditures, in an efficient and effective way. This attempt has tried to reduce public resources' waste, deficits, and cumulative debts in hospitals. ${ }^{5}$ Since FY2002 and until the troika agreement (FY2011), some of those attempts included the corporatization and merging (either vertical or horizontal) of public hospitals, ${ }^{14,15}$ the introduction of contracts between health care providers and the statutory monopsony, and the introduction of the public-private partnership concept in the (secondary) health care sector. ${ }^{16}$ A detailed identification and description of such policies (attempts) can be found in Nunes and Ferreira. ${ }^{48}$ Despite those measures and according to these authors, cost containment was not effective because the deficit in the public health sector tended to increase, and the objective of reducing expenses per medical act (or per patient) was not achieved.

Tables 1 and 2 show the growth of the Portuguese public and private expenditures in health care, as well as the financing and deficit of the NHS, for the period FY2002-FY2016. Figure 1 compares the evolution of GDP and public expenditures in health care for the same period. Between FY2002 and FY2010, public expenditures in health care increased about $€ 385$ million per year, which corresponds to a rate of $4.8 \%$ per year. The overall deficit in the public health care sector was approximately $€ 1,330$ million due to the accumulation of negative budgetary balances over the 8 years. Although the exact date cannot be precisely defined, the financial crisis in Portugal began circa FY2009. More than $€ 12,119$ million were available for health care in that year, or equivalently $€ 1,148$ per capita. From that budget, about 3 quarters (€8,900 million) were attributed to the Portuguese NHS. In FY2011, the public expenses grew 5.3\%, settling into $€ 9,400$ million, corroborating the hypothesis of public health underfunding.

Unlike public expenditures in health care, private expenditures had an overall increase of more than 59\% in the 8-year period FY2002-FY2010. During those 8 years, the average annual increase of private expenditures in health care was equal to $5.49 \%$ (€221.6 million per year).

The most recent MoU in Portugal was signed in FY2011. In view of that, the financing of health care, either public or private, suffered a considerable reduction between FY2011 and FY2015 (see Table 2). The public expenditures were yearly reduced by $€ 140$ million $(-2.7 \%)$, on average. It contrasts with the evolution of GDP within the same period (see Figure 1) and of public expenses in health care in the preceding 8-year period. Within FY2011-FY2015, the NHS cumulative deficit decreased due to injections of capital.

The troika agreement ended in December FY2015. In that year, more than $€ 10.5$ billion were available for the health care services (€1,029.6 per capita). From that budget, about $83 \%$ was attributed to the NHS. Nonetheless, expenses from the NHS grew 7.6\% in that year, to €9 billion, highlighting the public health sector underfunding (see Table 2). 
Table I. Public and Private Expenditures in the Health Care Sector in Portugal (FY2002-FY2010).

\begin{tabular}{|c|c|c|c|c|c|c|c|c|c|}
\hline & 2002 & 2003 & 2004 & 2005 & 2006 & 2007 & 2008 & 2009 & 2010 \\
\hline $\begin{array}{c}\text { Public health care } \\
\text { expenditures }\end{array}$ & 8,860 & 9,238 & 10,059 & 10,666 & 10,500 & 10,930 & $\mathrm{II}, 440$ & 12,119 & 12,327 \\
\hline $\begin{array}{l}\text { Annual } \\
\text { increase (\%) }\end{array}$ & 9.60 & 4.30 & 8.90 & 6.00 & -1.60 & 4.10 & 4.70 & 5.90 & 1.70 \\
\hline GDP (\%) & 6.20 & 6.30 & 6.60 & 6.70 & 6.30 & 6.20 & 6.40 & 6.90 & 6.90 \\
\hline $\begin{array}{c}\text { NHS health care } \\
\text { expenditures }\end{array}$ & 7,067 & 6,858 & 7,632 & 8,033 & 7,888 & 8,132 & 8,456 & 8,925 & 9,399 \\
\hline $\begin{array}{l}\text { Annual } \\
\quad \text { increase (\%) }\end{array}$ & 6.80 & -3.00 & 11.30 & 5.30 & -1.80 & 3.10 & 4.00 & 5.50 & 5.30 \\
\hline GDP (\%) & 5.00 & 4.70 & 5.00 & 5.10 & 4.70 & 4.60 & 4.70 & 5.10 & 5.20 \\
\hline NHS financing & 6,919 & 6,402 & 6,799 & 8,221 & 8,217 & $8,24 I$ & 8,322 & 8,709 & 9,187 \\
\hline $\begin{array}{l}\text { Annual } \\
\text { increase (\%) }\end{array}$ & 23.30 & -7.50 & 6.20 & 20.90 & -0.04 & 0.30 & 1.00 & 4.60 & 5.50 \\
\hline NHS deficit ${ }^{a}$ & -148 & -456 & -832 & 188 & 329 & 109 & -134 & -217 & -213 \\
\hline $\begin{array}{l}\text { Annual } \\
\text { increase (\%) }\end{array}$ & -84.80 & 207.70 & 82.70 & -122.60 & -75.30 & -66.90 & 223.00 & 61.50 & -1.90 \\
\hline Funding (\%) & -2.10 & -7.10 & -12.20 & 2.30 & 4.00 & 1.30 & -1.60 & -2.50 & -2.30 \\
\hline $\begin{array}{l}\text { Private health care } \\
\text { expenditure }\end{array}$ & 3,346 & 3,772 & 4,105 & 4,300 & 4,688 & 4,977 & 5,289 & 5,213 & 5,341 \\
\hline $\begin{array}{l}\text { Annual } \\
\text { increase (\%) }\end{array}$ & 0.50 & 12.70 & 8.80 & 4.80 & 9.00 & 6.20 & 6.30 & -1.40 & 2.50 \\
\hline GDP (\%) & 2.30 & 2.60 & 2.70 & 2.70 & 2.80 & 2.80 & 3.00 & 3.00 & 3.00 \\
\hline $\begin{array}{c}\text { Total health care } \\
\text { expenditures }\end{array}$ & 12,206 & 13,010 & 14,164 & 14,966 & 15,189 & 15,909 & 16,729 & 17,332 & 17,668 \\
\hline $\begin{array}{l}\text { Annual } \\
\quad \text { increase (\%) }\end{array}$ & 6.90 & 6.60 & 8.90 & 5.70 & 1.50 & 4.70 & 5.20 & 3.60 & 1.90 \\
\hline GDP (\%) & 8.60 & 8.90 & 9.30 & 9.40 & 9.10 & 9.10 & 9.40 & 9.90 & 9.80 \\
\hline
\end{tabular}

Sources: Instituto Nacional de Estatística (2010), Direção-Geral do Orçamento - Síntese de Execução Orçamental (2002-2010). Expenditures were expressed in million euros.

Abbreviations: GDP, gross domestic product; NHS, National Health Service.

${ }^{a} \mathrm{NHS}$ Deficit $=$ NHS Financing - NHS health care expenditures.

Private expenses in health care decreased annually by $€ 127$ million $(-2.3 \%)$, between FY2011 and FY2014. This fact reveals a change in the trend in the previous 8-year period. By FY2015, such expenditures grew $2.7 \%$ when compared with FY2014 but only $0.3 \%$ compared to FY2011. This behavior of private health care expenses may reveal the effects of the financial crisis, namely in what concerns the available household income's considerable reduction. It jeopardizes the access to the private care sector and the willingness for co-payments. 
Table 2. Public and Private Expenditures in the Health Care Sector in Portugal (FY20II-FY2016).

\begin{tabular}{cllllll}
\hline & 2011 & 2012 & 2013 & 2014 & 2015 & 2016 \\
\hline Public health care expenditures & 11,366 & 10,322 & 10,357 & 10,319 & 10,665 & 10,960 \\
Annual increase (\%) & -7.80 & -9.20 & 0.30 & -0.40 & 3.40 & 2.80 \\
GDP (\%) & 6.50 & 6.10 & 6.10 & 6.00 & 5.90 & 5.90 \\
NHS health care expenditures & 8,854 & 8,263 & 8,333 & 8,385 & 9,025 & 9,131 \\
Annual increase (\%) & -5.80 & -6.70 & 0.80 & 0.60 & 7.60 & 1.20 \\
GDP (\%) & 5.00 & 4.90 & 4.90 & 4.80 & 5.00 & 4.90 \\
NHS financing & 8,581 & 10,142 & 8,353 & 8,177 & 8,654 & 8,932 \\
Annual increase (\%) & -6.60 & 18.20 & -17.60 & -2.10 & 5.80 & 3.20 \\
NHS Deficit & -273 & 1879 & 21 & -208 & -372 & -199 \\
Annual increase (\%) & 28.20 & 789.50 & -98.90 & 1103.90 & 78.90 & -46.40 \\
Funding (\%) & -3.20 & 18.50 & 0.20 & -2.50 & -4.30 & -2.20 \\
Private health care expenditure & 5,424 & 5,420 & 5,119 & 5,297 & 5,441 & 5,585 \\
Annual increase (\%) & 1.60 & -0.10 & -5.60 & 3.50 & 2.70 & 2.60 \\
GDP (\%) & 3.10 & 3.20 & 3.00 & 3.10 & 3.00 & 3.00 \\
Total health care expenditures & 16,791 & 15,742 & 15,477 & 15,616 & 16,106 & 16,545 \\
Annual increase (\%) & -5.00 & -6.20 & -1.70 & 0.90 & 3.10 & 2.70 \\
GDP (\%) & 9.50 & 9.30 & 9.10 & 9.00 & 9.00 & 8.90 \\
\hline
\end{tabular}

Sources: Instituto Nacional de Estatística (2017), Direção-Geral do Orçamento - Síntese de Execução Orçamental (2002-2016). Expenditures are expressed in million euros.

Abbreviations: GDP, gross domestic product; NHS, National Health Service.

${ }^{a}$ NHS Deficit $=$ NHS Financing - NHS health care expenditures.

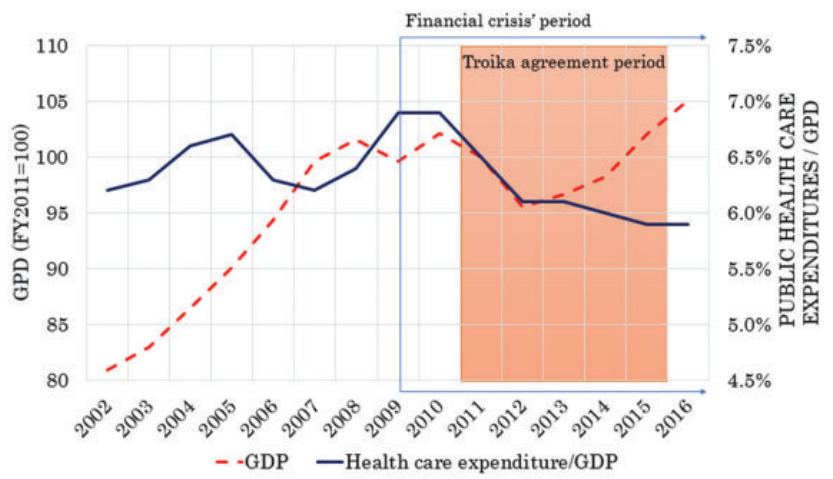

Figure I. Evolution of GDP and public health care expenditures/GDP ratio (FY2002-FY20 I6). Adapted from Instituto Nacional de Estatística (20I0), Direção-Geral do Orçamento - Síntese de Execução Orçamental (2002-2016). Abbreviations: GDP, gross domestic product. 
In FY2016, the Portuguese government introduced some health policies to reduce the NHS deficit and to increase its overall budget when compared with the austerity period. As a result, the public expenses with health care grew $2.8 \%$ compared to FY2015, keeping the same share of GDP (see Figure 1). The NHS financing grew $3.2 \%$, and its deficit decreased $2.2 \%$. Furthermore, the private expenses with health care grew $2.6 \%$ (see Table 2).

\section{Health Policies and the Memoranda of Understanding}

The MoU dictated the beginning of a set of austerity-related policies and structural measures to mitigate the impact of the crisis in public finances. The $\mathrm{MoU}$ detailed the general conditions of economic policy as embodied in the Council Execution Decision on granting of financial resources for assistance to Portugal. This decision specified that the first financial disbursement by the European Financial Stabilization Mechanism would be released with the MoU's entry into force. Subsequently, the council decision subjected the release of additional tranches based on quarterly reviews of the results achieved (progresses made) that took place during the troika period. ${ }^{9}$

Several reforms in the health care sector were included in the program for both central and regional governments to control and reduce expenditures, to mitigate waste, and to improve efficiency and effectiveness of health care providers.

Regarding the health care system financing, MoU-based policies reviewed and increased the moderating fees paid by citizens to the NHS providers. For instance, co-payments for primary care medical appointments changed from $€ 2.25$ to $€ 5.00$, whereas the tariff for an emergency visit to hospital rose from $€ 9.60$ to $€ 20.00$. Those policies also decreased the number of categories of citizens exempt from paying user fees, the contribution for nonemergency patients' transportation, ${ }^{10,11}$ and the tax deductions on health costs. Finally, those austerity measures promoted the self-financing of public health subsystems that no longer have access to public funds. ${ }^{4}$

MoU-based policies in the health sector also intervened at the level of drugs and pharmaceutical products. There was a review of the reference prices and tariffs, an imposition of ceiling prices for generic drugs, the reduction of entry barriers into the pharma market, the creation of compulsory electronic medicines prescription (to improve their monitoring), and the imposition of maximum profit margins for drugstores. In addition, the Portuguese government established a ceiling for costs associated with the pharmaceutical industry (roughly €2 billion). ${ }^{9}$

The following were measures adopted to promote efficiency in the health care system. First, the Ministry of Health implemented a centralized purchasing and supply system for drugs and medical devices used by the NHS providers. It is under the supervision of a specialized entity - Shared Services of the Ministry of 
Health (SSMH). Second, a code system and a common register for medical devices supplies by both the SSMH and the National Authority for Medicines and Health Products (INFARMED) were developed. Third, the capacity of the NHS was augmented, e.g., through increasing the number of beds. This measure was intended to reduce the use of the private sector. Fourth, prices paid by the NHS to the private sector for complementary diagnostics and therapeutics were revised and reduced. ${ }^{9}$

To enhance efficiency within the health sector, the MoU also imposed measures to control the expenditures of public hospitals. First, a schedule for paying arrears to domestic suppliers and an audit system were implemented. Transparency for appointing the board of directors was improved. This appointment should be based on merit, experience, and know-how. Some benchmarking reports based on access, quality, and efficiency indicators were developed, also contributing to improvement of transparency. The cooperation and integration of different technology and information systems for management data consultation in real time were settled. A human resources inventory per hospital and per medical specialty to assess current and future needs was introduced. Also, regarding clinical staff, some mobility rules were created and implemented. ${ }^{9}$

At the primary care level, only a few measures were imposed, aiming to mitigate needless access to secondary care (emergencies and specialty appointments). For that reason, the so-called Family Health Units were created. These entities are composed of teams of clinical staff, and their outcomes (improvement of the patients' well-being) are evaluated and rewarded, should they meet the goals predefined in contracts. Furthermore, general practitioners were incentivised to move to depopulated and deprived geographic areas (countryside) to reduce disparities in access to primary care services.

\section{The Application of Austerity Measures and Their Effects in the Health Sector}

Financial crises usually raise a number of serious concerns. Several authors refer to some adverse effects, including the loss of employment; the greater difficulty of entering the labor market; ${ }^{17,18}$ the risk of malnutrition; the increased mental disorders, alcohol consumption, and suicide; ${ }^{19,20}$ the poorer health protection; and the higher incidence of diseases. ${ }^{10}$ Other authors, however, point out that these crises may have a greater influence on high-risk groups, such as elderly, ${ }^{47}$ people living alone, immigrants, single mothers, and low-income people. ${ }^{10,19,44}$ Hence, it is compulsory that, in a period of public funding constraints, the effects of the crisis should be monitored by health authorities. Also, access to health care services should always be ensured, especially for the high-risk groups of citizens. 
According to the Portuguese National Institute of Statistics, by the end of FY2011 (when the financial aiding program took place), the income of nearly $42.5 \%$ of the Portuguese citizens was smaller than or equal to the so-called poverty threshold (whereas the average of EU28 was about $44 \%$ ). Between FY2012 and FY2015, that level rose 5.3\% in Portugal. About a fifth of those citizens were living under severe conditions of material deprivation. ${ }^{21,22}$ In FY2016, the dimension of that group reduced to levels close to FY2011, whereas the population living near the poverty line has kept nearly unchanged: $46.1 \%{ }^{21,22}$ Regarding FY2017, Statistics Portugal has foreseen a small decrease to $6.9 \%(-1.2 \%)$ of the population living in severe conditions of material deprivation. This prediction anticipates the economic recovery from the troika agreement period and the Portuguese economic growth after the exit of the procedure for excessive deficit. Even so, and compared to EU28, Portugal still exhibits the fourth highest level of citizens at risk of poverty. Above Portugal, we can find Hungary $(49.1 \%)$, Romania $(49.5 \%)$, and Greece $(52.9 \%) .{ }^{21}$

Evaluating the financial crisis effects in health care and public health is difficult in the short run because epidemiological and morbidity and mortality data have, in general, a latency period of 2 up to 5 years. ${ }^{23}$ That is, the effects of the financial crisis whose financial aid program ended by December FY2015 are still ongoing (FY2018). Hence, we cannot estimate the impact of the crisis and the MoU measures on health care outcomes, especially in chronic disease ${ }^{24}$ and transmissible diseases. ${ }^{24,25,26}$ However, we can study the impact of those measures on access to health care services, as well as on efficiency and quality of providers.

Regarding access to health care services, the increase of moderating fees resulted in a diminishing of health care services provided by the NHS, given the decreasing demand for health care (in line with the law of supply and demand). For instance, the number of general medical appointments in primary care decreased by $2.5 \%$ within FY2011-FY2015, despite the increase of citizens enrolled by a general practitioner (GP). In that period, the number of patients per GP increased from 1,550 to 1,900, mainly due to the reduction of the workforce. In terms of secondary health care (hospitals), emergencies decreased by $4.6 \%$, whereas surgeries and specialty appointments increased by $6.4 \%$ and $8.4 \%$, respectively. This is in line with the objective of reducing low complexity urgencies handled by hospitals and transferring them to the primary care centers, as they should be the first point of contact between the citizen and the NHS.

Barros and colleagues ${ }^{27}$ analyzed the impact of the financial crisis on demand for health care and health care services by the Portuguese citizens aged above 15 years old. According to those authors, $15.1 \%$ of interviewed citizens could not purchase some or all compulsory medicines. Additionally, $8.7 \%$ of citizens did not search for a medical appointment due to the lack of financial resources, and 5\% (resp. 6\%) missed the scheduled appointment because they had no money for transportation (resp. they did not want to lose a salary day). According to Sakellarides and colleagues, ${ }^{28}$ the change of co-payments could 
have been more equitable if they would be adjusted by the family income rather than by the services' prices.

Positive outcomes were observed in terms of efficiency of drugs delivery and pharmaceutical products' usage and related expenses. ${ }^{29}$ Indeed, there was a reduction of€668 million of those expenditures between FY2011 and FY2012. ${ }^{30,31}$ The average price of drugs supplied in ambulatory services decreased from $€ 15.19$ to 12.21 between FY2011 and FY2015. ${ }^{32}$ Furthermore, generic drugs increased their market share from $36.2 \%$ to $47.0 \%$ in the same period. ${ }^{33}$ In contrast, budgetary cuts of $€ 200$ million in the hospitals' funding between FY2011 and FY2012 did not result in efficiency gains. Instead, both technological and infrastructural investments were clearly missed. ${ }^{15}$ Changes in public administration, including cuts in wages and overtime payments, had a significant impact on clinical staff. Evidence suggests an increased emigration of young physicians and nurses, hasty retirements, and migration of clinical staff from the public to the private sector. ${ }^{10}$

Recently, Correia and colleagues ${ }^{34}$ analyzed the effects of the financial crisis on health and health care, using 3,442 inquiries to physicians working within the Portuguese NHS. Results suggest improvements in efficiency and effectiveness, without endangering quality of delivered care. Nevertheless, the authors concluded that such efficiency improvements could result from recurring material shortage in public institutions and a larger pressure to reduce provision carerelated expenses, including prescribed medication. In fact, there was a refusal to introduce innovative treatments in several providers, a lack of compulsory drugs for inpatients, and the ending of some therapies.

\section{An Econometric Analysis}

To complement and corroborate the previous analysis, we apply some econometric models to a set of Portuguese public hospitals. These models determine whether the Portuguese public hospitals have improved their performance over the period of 4 years, FY2013-FY2016. This period corresponds to the last 3 years associated with the troika agreement period and the first year after external intervention. It should be noticed that this period was considered because of data availability. Also, the measures introduced by MoU have likely some late effects that would be observed also in FY2016, i.e., after intervention.

To study the evolution of hospitals performance in the considered period, we used a directional-based Data Envelopment Analysis (DEA), alongside the Hicks-Moorsteen (HM) productivity index. ${ }^{35}$ The HM can be decomposed into several indexes: efficiency spread change (ES), productivity gap (PG), scale efficiency evolution (SEE), and change of consumed resources, delivered services, and (un)desirable variables related to quality. Details are as follows.

DEA computes optimal targets for inefficient hospitals based on the linear combination of the Pareto-efficient ones. These targets are, then, used to 
compute the augmented Hicks-Moorsteen Index (HM) as proposed by Ferreira and Marques. ${ }^{35}$ The HM is a true total factor productivity index (TFPI), in opposition to the widely spread Malmquist index, which is a TFPI if (and only if) the production technology globally exhibits constant returns to scale, i.e., hospitals are assumed to be in their own optimal scale. This assumption is, however, doubtful in practice. The HM index does not make this assumption, it can couple all inefficiency sources because it is based on targets rather than the distances to the empirical efficient frontier, and it is indefinitely decomposable and multiplicatively complete. ${ }^{35}$ In short, it is multiplicatively decomposed into an efficiency spread index, ES, a productivity gap index, PG, and a scale economies exploitation index, SEE. Meanwhile, the PG index can be decomposable into as many indexes as the number of groups of variables: inputs, $\Delta \mathcal{X}$, outputs, $\Delta \mathcal{Y}$, desirable process variables, $\Delta \mathcal{D}$, and undesirable process variables, $\Delta \mathcal{U}$.

Consider 2 moments of time, $t$ and $\tau$, such that $\tau>t$. Gains (or losses) of productivity over that period, $\Delta=\tau-t>0$, are measured by $H M_{t \tau}>1$ (or $<1)$. Since

$$
H M_{t \tau}=E S_{t \tau} \cdot P G_{t \tau} \cdot S E E_{t \tau}=E S_{t \tau} \cdot \Delta \mathcal{X}_{t \tau} \cdot \Delta \mathcal{Y}_{t \tau} \cdot \Delta \mathcal{D}_{t \tau} \cdot \Delta \mathcal{U}_{t \tau} \cdot S E E_{t \tau}
$$

productivity improvements result from (i) efficiency gains, $E S_{t \tau}>1$, (ii) approaches to the optimal scale, $S E E_{t \tau}>1$, (iii) reduction of resources consumption by benchmarks, $\Delta \mathcal{X}_{t \tau}>1$, (iv) increasing of delivered services by benchmarks, $\Delta \mathcal{Y}_{t \tau}>1$, (v) improvement of desirable process variables of care, $\Delta \mathcal{D}_{t \tau}>1$, and (vi) improvement of undesirable variables, $\Delta \mathcal{U}_{t \tau}>1$. Mathematical details can be found in Ferreira and Marques. ${ }^{35}$

Data were provided by the official source of the Ministry of Health (http:// benchmarking.acss.min-saude.pt/) and included variables classified as consumed resources (inputs), delivered services (outputs), quality of care (appropriateness and safety), and access (timeliness). We used these data to construct 4 nonparametric piecewise linear frontiers, one for each year from FY2013 to FY2016, using DEA. Based on data availability, we considered the following variables:

\section{Inputs}

- Staff costs, $\mathrm{X}_{1}$ - expenses with doctors, nurses, and other staff, either clinical or not, and excluding outsourcing

- Operating costs, $\mathrm{X}_{2}$ - operational costs excluding staff, outsourcing, and costs of goods sold and consumed

- Costs of goods sold and consumed, $\mathrm{X}_{3}$ - expenses with drugs and clinical material

- Costs with outsourcing, $\mathrm{X}_{4}$, including external labor

- Beds, $\mathrm{X}_{5}$ - total beds occupied within a year in nurseries 
- Doctors, $\mathrm{X}_{6}$ - full-time equivalent (FTE) number of doctors

- Nurses, $\mathrm{X}_{7}-$ FTE number of nurses

- Hospital days, $\mathrm{X}_{8}$ - total number of days spent by all inpatients, as time is a resource that should be consumed.

2. Outputs (desirable)

- Inpatient discharges, $\mathrm{Y}_{1}$, adjusted by the inpatient Case-Mix Index (CMI)

- Emergency cases, $\mathrm{Y}_{2}$, adjusted by the medical CMI

- First medical appointments, $\mathrm{Y}_{3}$, adjusted by the medical CMI

- Follow-up medical appointments, $\mathrm{Y}_{4}$, adjusted by the medical CMI

- Outpatient (minor) surgeries, $\mathrm{Y}_{5}$, adjusted by the medical CMI

- Conventional (major) surgeries, $\mathrm{Y}_{6}$, adjusted by the surgical CMI

- Urgent surgeries, $\mathrm{Y}_{7}$, adjusted by the surgical CMI

- Number of births, $\mathrm{Y}_{8}$

3. Desirable variables of process of care (extra desirable outputs)

- Outpatient surgeries per potential outpatient procedure, $\mathrm{D}_{1}$, as minor surgeries should be favored (for the sake of resources exploitation efficiency), particularly whenever it is the most appropriate scenario for the patient

- Rate of hip surgeries on elderly, in the first 48 hours after hip fracture, $\mathrm{D}_{2}$ - it measures how timely the health care provider is and how safe the eldest inpatients are from potential hazardous events following delayed surgeries

- Rate of first medical appointments within the maximum ensured (legislated) response time per first medical appointment, $\mathrm{D}_{3}$, as a measure of timeliness and barrier to access to secondary health care providers (because outpatients enter this level of care by referral or by emergency)

4. Undesirable variables of process of care (extra undesirable outputs)

- Rate of decubitus ulcers in bedridden, $\mathrm{U}_{1}$

- Rate of pulmonary embolism and deep vein thrombosis, $\mathrm{U}_{2}$

- Rate of postoperative septicemia, $\mathrm{U}_{3}$

- Rate of in-hospital death rates for low severity levels, $\mathrm{U}_{4}$

- Rate of readmissions within 30 days after discharge, $\mathrm{U}_{5}$

- Inpatients staying more than 30 days in the inpatient services, $\mathrm{U}_{6}$

- Rate of caesarean sections per delivery, $\mathrm{U}_{7}$

- Rate of caesarean sections on term cephalic presentations, $\mathrm{U}_{8}$

- Rate of vaginal deliveries after caesarean sections, $\mathrm{U}_{9}$

Portugal is a small country, thus with only a few public hospitals. Even though, several mergers have occurred in the past few years, narrowing down the number of secondary health care providers. On the one hand, we considered only the singular hospitals and the hospital centers (horizontally merged entities). On the other hand, we excluded local health units (LHU), public-private partnerships (PPP), and specialized hospitals, such as oncology centers and psychiatric hospitals. LHUs result from the vertical integration of a hospital and some primary care centers, and publicly available data regards the entire 
structure. Including these entities in a benchmarking exercise would certainly introduce unfair comparisons. PPPs are not forced to publish their expenditures. Given the lack of data for these entities, we opted to remove them from our dataset as well. Finally, highly differentiated hospitals have a production technology that is totally different from the undifferentiated health care providers. This means that including the former hospitals in the analysis would likely produce efficient frontiers that do not translate the true production frontier. In other words, these hospitals are not directly comparable with the undifferentiated ones. By these reasons, our sample contains 108 undifferentiated hospitals and hospital centers homogenously distributed across the 4 years of analysis. No outlier was detected, even after a super-efficiency analysis.

We had as many variables as hospitals in the sample. Meanwhile, nonparametric models have a dimensionality problem related to the number of the variables and the sample's size. In other words, the results' resolution is lost when there are too many variables when compared to the number of hospitals in the dataset. Past evidence suggests that the number of hospitals should be, at least, 3 times the number of variables. Since it is not possible to increase the number of hospitals in the dataset, we used Principal Component Analysis (PCA). It is a widely spread technique that narrows down the number of variables, with no significant loss of information, and simultaneously removes redundant information arising, for instance, from highly correlated variables. Therefore, after standardizing variables by dividing them by their standard deviation $(\sigma)$, we applied PCA to the inputs, $\mathcal{X}=\operatorname{PCA}\left(\frac{X}{\sigma(X)}\right)$, to the outputs, $\mathcal{Y}=\operatorname{PCA}\left(\frac{Y}{\sigma(Y)}\right)$, to the desirable process variables, $\mathcal{D}=\operatorname{PCA}\left(\frac{X}{\sigma(X)}\right)$, and to the undesirable process variables, $\mathcal{U}=\operatorname{PCA}\left(\frac{U}{\sigma(U)}\right)$. These new variables (first component of each PCA) can explain, at least, $88 \%$ of the sample's original variability, after redundancy removal. In other words, these 4 new variables are very good proxies of hospitals behavior in terms of resources consumption, volume of delivered services, quality of care, and access to the appropriate and timely care.

When we applied those 4 variables to both the DEA and the HM index, we obtained the overall productivity evolution of Portuguese public hospitals, as well as the decomposed indexes supporting that evolution. Routines were developed in Matlab ${ }^{\circledR}$. Evidence is presented in Figure 2. Ninety-five percent confidence intervals are represented as "whiskers." If those intervals contain the unit, then the index is not significantly different from 1 (in the statistical sense), i.e., neither improvement nor worsening of productivity can be detected.

According to our results, there was a slightly decrease of productivity within the period FY2013-FY2014 $\left(\mathrm{HM}_{2013 / 2014}<1\right)$, with a recovery in the next triennium $\left(\mathrm{HM}_{2014 / 2015} \times \mathrm{HM}_{2015 / 2016}>1\right)$. Overall, there was a small productivity increase between FY2013 and FY2016 because $\mathrm{HM}_{2013 / 2016}=\mathrm{HM}_{2013 / 2014} \times$ 


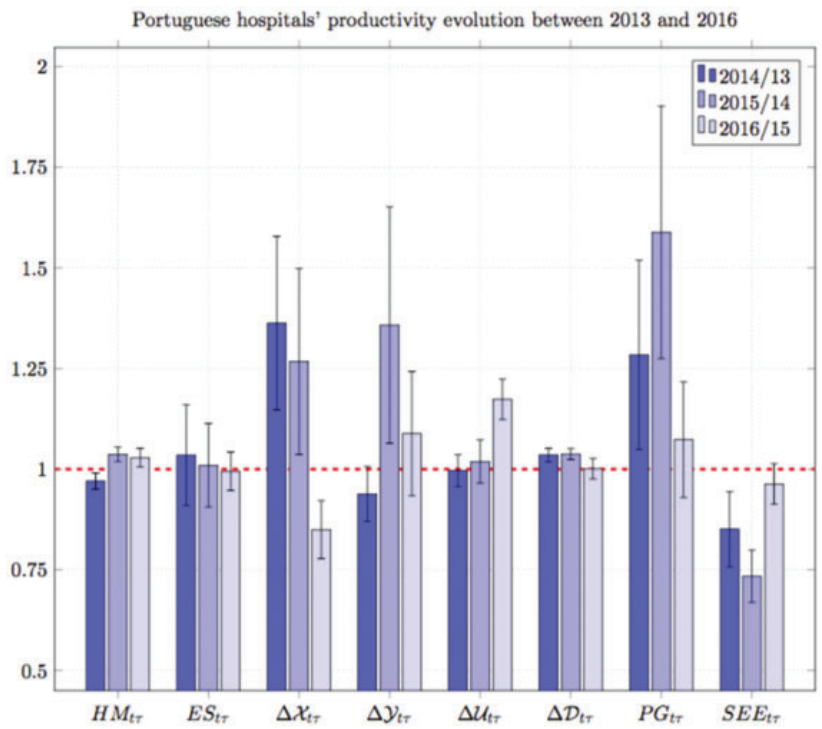

Figure 2. Productivity evolution of Portuguese public hospitals, FY20I3-FY20I6. Source: authors.

$\mathrm{HM}_{2014 / 2015} \times \mathrm{HM}_{2015 / 2016}>1$. This is not the result of efficiency changes, as $E S_{t \tau} \approx 1$ for $t, \tau=2013, \ldots, 2016, t \neq \tau$. In other words, there was no efficiency change of hospitals during the considered period. Mathematically, the relative position of hospitals regarding the annual efficient frontier did not significantly change during the considered period. Furthermore, the productivity change was negatively influenced by the decreasing of the scale economies exploitation: see index SEE, which is smaller than 1 between FY2013 and FY2015, and not different from 1 in the last biennium - thus, $\mathrm{SEE}_{2013 / 2016}<1$. Currently, hospitals are farther from the optimal scale than they were before FY2013 because $\mathrm{SEE}=\mathrm{SEE}_{2013 / 2014} \times \mathrm{SEE}_{2014 / 2015} \times \mathrm{SEE}_{2015 / 2016}$ is globally smaller than 1. That is, since FY2013, hospitals have repeatedly lost their capacity of exploiting scale economies.

In view of that, the productivity change within FY2013-FY2016 resulted from improvements on the technology, because $P G_{t \tau}$ was significantly larger than 1 , at least between FY2013 and FY2015 ( $\mathrm{PG}_{2013 / 2014}$ and $\mathrm{PG}_{2014 / 2015}$ larger than 1). The first biennium was marked by the reduction of consumed resources $\left(\Delta \mathrm{X}_{2013 / 2014}>1\right)$, perhaps resulting from the financial crisis, without substantial changes in delivered services $\left(\Delta \mathrm{Y}_{2013 / 2014} \approx 1\right)$ or improvements in terms of undesirable dimensions of care $\left(\Delta \mathrm{U}_{2013 / 2014} \approx 1\right)$. Meanwhile, the performance of hospitals in terms of desirable dimensions was significantly improved in that biennium $\left(\Delta \mathrm{D}_{2013 / 2014}>1\right)$. Similar trends were observed regarding the period 
FY2014-FY2015, although a considerable growth of provided services was observed $\left(\Delta Y_{2014 / 2015}>1\right)$. This means that one can motivate reduction of expenses without worsening the delivery of health care services and their quality. Finally, the efficient frontier between FY2015 and FY2016 did not shift, motivated by an increase of resources consumption which seems to be associated with an improvement of quality of the delivered services. Since the position of hospitals regarding the annual frontier did not change $\left(\mathrm{ES}_{2013 / 2014} \times \mathrm{ES}_{2014 / 2015} \times \mathrm{ES}_{2015 /}\right.$ ${ }_{2016} \approx 1$ ), and this frontier significantly and positively shifted during the considered period (PG $>1$ between FY2013 and FY2015 and PG $=1$ between FY2015 and FY2016), then the overall performance of hospitals increased and hospitals from FY2016 outperform their counterparts from FY2013.

\section{Current Policies to Retrieve the National Health Service}

The policy redefinition following the financial crisis was a wasted opportunity to implement reforms to induce access, quality, and efficiency in the Portuguese NHS. Indeed, as suggested by our econometric analysis, no meaningful performance improvement was achieved for hospitals within the period FY2013FY2015. Additionally, the Portuguese Observatory on Health Systems did warn the government of the need to promote a strategic plan to predict the side effects of such a crisis in the primary care sector. That plan would include a better and stronger integration with other health care providers and other care levels, including the secondary one. ${ }^{36}$ Nonetheless, the suggestion was not heeded.

In FY2016, the current Ministry of Health concluded that the crisis not only did not solved but also worsened some problems existing in the NHS, including

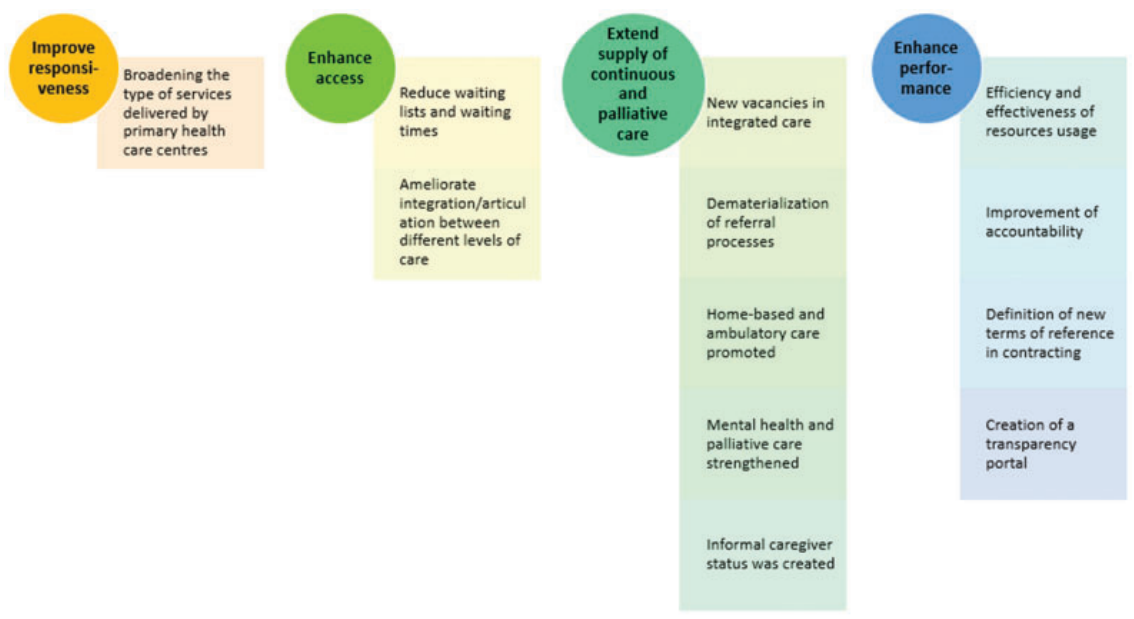

Figure 3. Main strategies of the current government to retrieve the NHS (FY20I6 onwards). 
the loss of responsiveness to health care demand, the lack of investments, and the increased barriers to access. ${ }^{37}$ For this reason, a new 4-year strategy (FY2016-FY2019) was implemented to reform the NHS. It is summarized in Figure 3. First, this strategy aimed to improve the responsiveness to citizens - greater elasticity in primary health care with the introduction of medical tests such as routine laboratory exams, X-rays, electrocardiography, oral health examinations, and visual health tests. Secondly, the access of citizens to the appropriate and timely care had to be enhanced. To do so, barriers to access had to be mitigated, e.g., by reducing waiting lists and waiting times for medical appointments and emergencies and by ameliorating the integration and articulation between different levels of care and between different entities delivering the same care level. Thirdly, the supply of continuous and palliative care had to be extended. For such a purpose, new vacancies in integrated care were created; referral processes were dematerialized; home-based and ambulatory care were promoted; mental health and palliative care component were strengthened; and the concept of informal caregiver was introduced. Furthermore, in line with the government's strategy during the troika agreement period, the efficiency and effectiveness of the use of NHS resources had to be increased. For example, improving the accountability, defining new terms of reference in contracts, and creating an NHS-based transparency portal were 3 components of that strategy. ${ }^{37}$

In terms of public health promotion, some tactics have been implemented to induce healthier life styles (in line with the National Health Plan) (see Figure 4). For instance, a Health Literacy National Program was created in FY2016 to identify, validate, support, and progressively disseminate good practices in both health literacy and self-care. A program to control and to mitigate infectious diseases, epidemics, and multi-drug resistant infections was also introduced, alongside some preventive measures against the tobacco consumption, e.g., anti-tobacco drug reimbursement and tobacco restriction measures in public places. ${ }^{37}$
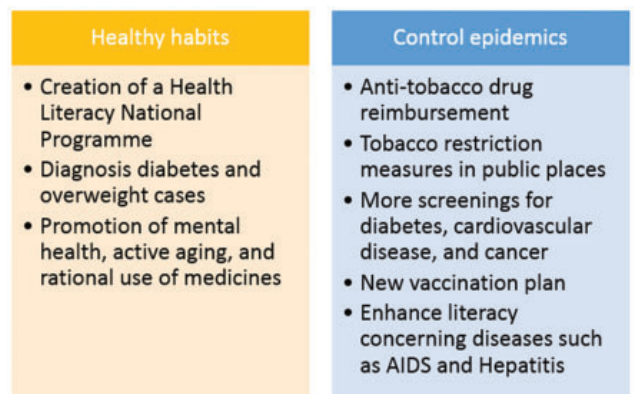

Figure 4. Summary of the main strategies undertaken for public health (FY2016 onwards). 
To reduce inequities on access to health care, the services responsiveness has been improved by reducing co-payments, by increasing the number of citizens exempt from them (e.g., firefighters and donors of blood or organs), and by providing free (home-to-health care provider and vice versa) transportation for deprived citizens. ${ }^{38}$

The customers' opinion and satisfaction are also a major concern of the current government. The more satisfied the patient is, the expectedly better will be the outcomes of care. Therefore, implementing systems that control for the (dis)satisfaction of users and identify priority areas is a compulsory measure. For instance, Ferreira and colleagues ${ }^{39}$ extended and applied a linear programming tool, known as MUSA (Multicriteria Satisfaction Analysis) to identify the priory areas to improve the satisfaction of outpatients seen in the medical appointments' service. Those authors proposed multiple strategies, but the critical one is, as expected, to reduce waiting times. Moreover, past experiences may dictate future demand: a dissatisfied patient is unlikely to demand future care from the same provider. Therefore, citizens are now free to choose where they want to be treated, ${ }^{40}$ according to a referral system. Given the current financing system, the citizens' free choice is likely to induce quality enhancements of delivered care.

Primary health care is a priority in the annual strategy of the Ministry of Health. In FY2015, nearly a 10th of all Portuguese citizens had no designated GP. In FY2016, this scenario changed for half a million Portuguese citizens. Furthermore, oral and ophthalmic care were integrated into the primary care level (pilot projects). Additional family health units were created. ${ }^{38}$ In the short run (FY2018 and FY2019), one may expect that all citizens should have a designated GP. Moreover, oral and ophthalmic care services should be extended to the entire Portuguese mainland, and investments should be made to recover degraded infrastructures and to update technology. ${ }^{37}$

The management, valorization, and motivation of human resources is another priority area of this strategy. By December FY2017, NHS hired more than 5,800 health professionals. The role of health professionals and their responsibilities were valued. In short, the clinical staff admission process was simplified, and some incentives for the geographical mobility of doctors and nurses to deprived regions were introduced to reduce access disproportions. ${ }^{41}$

As part of the overall improvement of NHS governance, the current policy aims to reinforce efficient management strategies in management contracts by introducing incentives. The current health policy also intends to improve transparency, as well as the timely disclosure of information regarding the performance of the NHS. In this sense, hospitals gain special relevance as does the drug industry. At the level of hospital management, one should promote and reward the most efficient hospitals and should develop a process of sharing resources between providers, such that patients are referred to other hospital units that are willing to receive them. Thus, waiting lists for consultation or surgery may be shortened. ${ }^{42}$ For the future, the Ministry of Health plans to investment in new equipment, to 
build new hospital PPPs, and to increase patient referrals to complementary diagnostic facilities and therapeutic services. ${ }^{41}$

About improving services quality in terms of their timeliness and appropriateness, the development of good practices and patient safety is one of the priorities, avoiding cases of complications and deaths arising from poor provision. Preventive plans have already been implemented to monitor quality in the NHS by an extensive list of performance indicators, like the one used in section 5 and by Ferreira and Marques. ${ }^{49}$

Another priority challenge is the commitment to information and communication systems that monitor the performance of the NHS providers and promote the sharing of the patients' clinical process among all health care providers. Additional areas of focus are the fight against fraud and corruption in prescriptions, the reduction of charges in the private sector, the sustainability of cost reduction through a centralized purchasing process, and the investment in highend equipment differentiation to replace the existing ones.

\section{Conclusions}

The financial, economic, and social crisis in Portugal forced the government to reduce public financing, particularly in the health sector, through a set of measures included within an MoU. These measures promoted, on the one hand, the rationalization of resources. ${ }^{43-45}$ On the other hand, these measures have increased the barriers to access to health care, as well as divestments in equipment and infrastructures. In addition, the crisis had indirect effects on the health of the population by reducing disposable household's income.

As for the effects on the health status of the Portuguese citizens, there are no concrete evaluations, on the one hand, because the economic downturn is still very recent, and, on the other hand, because the government has not implemented yet a system to monitor the impact of austerity in the population's health status. Furthermore, evidence-based monitoring should have been developed to address the negative effects, especially, in the most vulnerable groups.

Since FY2016, the country has recovered financially, through the deficit reduction, unemployment decreasing, and investment in health care increasing, hiring of human resources, and rehabilitation of infrastructures and equipment.

\section{Acknowledgments}

The authors would like to thank one anonymous referee whose kindly and beneficial comments significantly improved this paper's quality, clarity, and structure. The contents of the paper are the authors' own responsibility. The usual disclaimer applies. 


\section{Declaration of Conflicting interests}

The authors declared no potential conflicts of interest with respect to the research, authorship, and/or publication of this article.

\section{Funding}

The authors received no financial support for the research, authorship, and/or publication of this article.

\section{ORCID iD}

Diogo Cunha Ferreira (D) http://orcid.org/0000-0001-5418-9337

\section{References}

1. Amado C, Santos S. Challenges for performance assessment and improvement in primary health care: the case of the Portuguese health centers. Health Policy. 2009;91(1):43-56.

2. Barros P, Machado S, Simões J. Portugal. Health systems review. Health Syst Transit. 2011;13(4):1-179.

3. Mossialos E, Dixon A.Funding health care: an introduction. In: Mossialos E, Dixon A, Figueras J, Kutzin J, eds. Funding Health Care: Options for Europe. Buckingham, England: European Observatory on Health Care Systems Series; 2002; 2-24.

4. Simões J, Augusto G, Fronteira I, Hernández-Quevedo C. (2017). Portugal. Health systems review. Health Syst Transit. 2017;19(2):1-211.

5. Barros P. Health policy reform in tough times: the case of Portugal. Health Policy. 2012;106,17-22.

6. Eurostat. GDP and main components (output, expenditure and income). http:// appsso.eurostat.ec.europa.eu/nui/show.do?dataset=nama_10_gdp\&lang=en. Published 2017. Accessed January 4, 2019.

7. INE. Conta Satélite da Saúde. https://www.ine.pt/xportal/xmain?xpid=INE\&xpgid $=$ ine_destaques\&DESTAQUESdest_boui=281092804\&DESTAQUESmodo=2. Accessed January 4, 2019.

8. Eurostat. Government finance statistics. Government deficit and debt. http://appsso. eurostat.ec.europa.eu/nui/show.do?dataset=gov_10dd_edpt1\&lang=en. Published 2017. Accessed January 4, 2019.

9. Portugal - Memorandum of understanding on specific economic policy conditionality. 17 May 2011. https://resistir.info/portugal/memo_troika.pdf. Accessed February $17,2018$.

10. Karanikolos M, Mladovsky P, Cylus J, et al. Financial crisis, austerity, and health in Europe. Lancet. 2013;381(13):1323-1331.

11. Augusto G. Cuts in Portugal's NHS could compromise care. Lancet. 2012; 379:400.

12. Simões J, Barros P, Pereira J, eds. Relatório Final da Comissão para a Sustentabilidade do Financiamento do SNS de 2006/2007. http://www.sg.min-saude.pt/NR/rdonlyres/ 050CB0A2-7ACC-4975-A1E4-4312A1FBE12D/0/RelatorioFinalComissao SustentabilidadeFinanciamentoSNS.pdf. Accessed February 17, 2018. 
13. Oliveira M, Pinto C. Health care reform in Portugal: an evaluation of the NHS experience. Health Econ. 2005;14:203-220.

14. Simonet D. The new public management theory and the reform of european health care systems: an international comparative perspective. Int $J$ Public Admin. 2011;34(12):815-826.

15. Ferreira, D., Marques, R.C. Did the corporatization of Portuguese hospitals significantly change their productivity? Eur J Health Econ. 2015;16(3):289-303.

16. Nunes A. Reforms in Portuguese Hospital Management: Analysis of the Effects of Entrepreneurship [doctoral Thesis]. Lisbon, Portugal: Lisbon University; 2016.

17. Ghoshray A, Ordóñez J, Sala H. Euro, crisis and unemployment: youth patterns, youth policies? Econ Model. 2016;58:442-453.

18. Guichard S, R. Assessing the Impact of the Financial Crisis on Structural Unemployment in OECD Countries. France: OECD Economics Department Working Papers, Paris.

19. McKee M, Karanikolos M, Belcher P, Stuckler D. Austerity: a failed experiment on the people of Europe. Clin Med. 2012;12:346-350.

20. Barr B, Taylor-Robinson D, Scott-Samuel A, McKee M, Stuckler D. Suicides associated with the 2008-10 economic recession in England: time trend analysis. BMJ. 2012;345:e5142.

21. Pordata database. European Household Panel - European statistics on income and living conditions. https://www.pordata.pt/DB/Europa/Ambiente+de+Consulta/ Tabela. Accessed January 4, 2019.

22. INE - National Institute of Statistics. Survey on living conditions and income. https://www.pordata.pt/DB/Portugal/Ambiente+de+Consulta/Tabela. Accessed January 4, 2019.

23. Stuckler D, Basu S, McKee M, Suhrcke M. Responding to the economic crisis: a primer for public health professionals. J Public Health. 2010;32(3):298-306.

24. McKee M. The consequences of economic crises and the responses to them for population health. Eur J Public Health. 2011;21(Suppl. 1):7.

25. Rechel B, Suhrcke M, Tsolova S, et al. Economic crisis and communicable disease control in Europe: a scoping study among national experts. Health Policy. 2011;103(2-3):168-175.

26. Suhrcke M, Stuckler D, Suk JE, Desai M, Senek M, McKee M. The Impact of economic crises on communicable disease transmission and control: a systematic review of the evidence. PLoS One. 2011;6(6):e20724.

27. Barros P, Afonso H, Martins B, e Pereira D. Impacto das taxas moderadoras na utilização de serviços de saúde. Lisbon, Portugal: Nova School of Business and Economics; 2013.

28. Sakellarides C, Castelo-Branco L, Barbosa P, Azevedo H. The Impact of the Financial Crisis on the Health System and Health in Portugal. Denmark, Copenhagen: European Observatory on Health Systems and Policies; 2014.

29. Barros P. Pharmaceutical market reforms in Portugal under the memorandum of understanding. Eurohealth. 2012;18:33-36.

30. Portuguese Observatory on Health Systems. Crisis and Health: A Country in Distress. Lisbon, Portugal: Portuguese Observatory on Health Systems; 2012. Spring Report. 
31. Directorate-General of Budget. Síntese da execução orçamental [Summary of execution of state budget]. Lisbon, Portugal: Ministério das Finanças Direção-Geral do Orçamento; 2012.

32. PORTAL SNS. Average price of medication packaging. https://transparencia.sns. gov.pt/explore/dataset/preco-medio-por-embalagem/table/?refine.tem po $=2011 \&$ sort $=$ tempo. Accessed January 4, 2019.

33. PORTAL SNS. Supply of generic drugs. https://ransparencia.sns.gov.pt/explore/ dataset/genericos/?sort=tempo. Accessed January 4, 2019.

34. Correia T, Carapinheiro G, Silva J, Vieira J. The Portuguese Health System in the Time of the Troika: The Experience of Physicians. Lisbon, Portugal: ISCTE-IUL/ Order of Physicians; 2015.

35. Ferreira DC, Marques RC. Malmquist and Hicks-Moorsteen productivity indexes for clusters performance evaluation. Int $J$ Inf Technol Decis Mak. 2016;15(5):1015-1053.

36. Portuguese Observatory on Health Systems. Health - Denial syndrome. Lisbon, Portugal: Portuguese Observatory of Health Systems; 2012. Spring 2014 Report. http://dspace.uevora.pt/rdpc/handle/10174/7263. Accessed October 29, 2014.

37. Portugal. Program of the XXI Constitutional Government. Lisbon, Portugal: Assembleia da República Portuguesa; 2015.

38. ACSS. Central Administration of the Health System. Report on Access to health care of the NHS; 2016. https://www.sns.gov.pt/wp-content/uploads/2016/07/Relat $\%$ C3\% B3rio-Acesso-SNS_2016-vf.pdf. Accessed January 4, 2019.

39. Ferreira DC, Marques RC, Nunes AM, Figueira JR. Patients' satisfaction: the medical appointments valence in Portuguese public hospitals. Omega Int J Manag Sci. 2017;80:58-76.

40. Simões J, Augusto G, Fronteira I. Introduction of freedom of choice for hospital outpatient care in Portugal: implications and results of the 2016 reform. 2017. Health Policy. 2017;121(12):1203-1207.

41. Ministry of Health Portugal. Explanatory note State budget for health. https://www. parlamento.pt/sites/COM/XIIILeg/5COFMA/OE2018/Paginas/default.aspx. Accessed: February 17, 2018.

42. ACSS - Central Administration of the Health System. Terms of reference for contracting health care in 2016. http://www.acss.min-saude.pt//wp-content/uploads/ 2016/07/Contratualizacao-HH-ULS-Termos-Referencia_VF.pdf. Accessed January 4, 2019.

43. Cylus J, Mladovsky P, McKee M. Is there a statistical relationship between economic crises and changes in government health expenditure growth? An analysis of twentyfour European countries. Health Serv Res. 2012;47(6):2204-2224.

44. Karanikolos M, Heino P, McKee M, Stuckler D, Legido-Quigley H. Effects of the global financial crisis on health in high-income OECD countries. Int $J$ Health Serv. 2016;46(2):208-240.

45. Dauderstadt M, Keltek C. Crisis, austerity, and cohesion: Europe's stagnating inequality. Int J Health Serv. 2015;45(1):25-31.

46. Perelman, J, Felix, S., Santana, R. The great recession in Portugal: impact on hospital care use. Health Policy. 2015;119(3):307-315. 
47. Doetsch, J, Pilot, E, Santana, P, Krafft, T. Potential barriers in healthcare access of the elderly population influenced by the economic crisis and the troika agreement: a qualitative case study in Lisbon, Portugal. Int J Equity Health. 2017;16:184.

48. Nunes, A, Ferreira, D. The health care reform in Portugal: outcomes from both the New Public Management and the economic crisis [published online ahead of print August 15, 2018]. Int J Health Plann Manage. doi:10.1002/hpm.2613

49. Ferreira, D, Marques, R. Do quality and access to hospital services impact on their technical efficiency? [published online ahead of print July 31, 2018]. Omega Int J Manage Sci. doi:10.1016/j.omega.2018.07.010.

\section{Author Biographies}

Alexandre Morais Nunes, PhD, is a Professor of Public Administration at CAPP (Public Policy Management Centre), Instituto Superior de Ciências Sociais e Políticas, Universidade de Lisboa, Portugal, and the technical advisor of the (Portuguese) Minister of Health. His research interests include public administration and health systems' performance.

Diogo Cunha Ferreira, $\mathrm{PhD}$, is a researcher at CERis, Instituto Superior Técnico, Universidade de Lisboa, Portugal. His research interests include performance assessment of health care systems through benchmarking models as well as the evaluation of patients' satisfaction and the priority areas deserving enhancements due to low satisfaction levels

Adalberto Campos Fernandes, PhD, served as Minister of Health from November 2015 to October 2018. He is a professor at the Escola Nacional de Saúde Pública, New University of Lisbon. His research interests include public administration and health care systems. 